\title{
Electron beam assisted chemical vapor deposition of $\mathrm{SiO}_{2}$
}

\author{
L. R. Thompson, J. J. Rocca, K. Emery, P. K. Boyer, and G. J. Collins \\ Department of Electrical Engineering, Colorado State University, Fort Collins, Colorado 80523
}

(Received 31 May 1983; accepted for publication 29 July 1983)

\begin{abstract}
We have demonstrated electron beam assisted chemical vapor deposition of silicon dioxide films on silicon substrates via electron impact dissociation of $\mathrm{SiH}_{4}$ and $\mathrm{N}_{2} \mathrm{O}$ gas. Dissociation of reactant gases occurs primarily in the confined planar region of the electron beam created plasma. Electron beam deposited $\mathrm{SiO}_{2}$ films have been categorized in terms of their electrical, physical, and chemical properties.
\end{abstract}

PACS numbers: $81.15 . \mathrm{Gh}, 61.80 . \mathrm{Fe}, 73.60 . \mathrm{Hy}, 77.55 .+\mathrm{f}$

A new low-temperature $\left(150-500^{\circ} \mathrm{C}\right)$ method to deposit microelectronic thin films using plasma generated direct current electron beams has been investigated. Films of silicon dioxide have been deposited on silicon wafers by electron beam dissociation of nitrous oxide $\left(\mathrm{N}_{2} \mathrm{O}\right)$ and $5 \%$ silane $\left(\mathrm{SiH}_{4}\right)$ diluted in nitrogen. $\mathrm{SiO}_{2}$ films grown with conventional thermal processes and rf plasma assisted chemical vapor deposition (CVD) have well categorized properties and thus provide a vehicle to compare the films deposited with the new electron beam CVD technique.

Deposited silicon dioxide $\left(\mathrm{SiO}_{2}\right)$ films are presently used for active area isolation, ${ }^{1}$ as an interlayer dielectric between interconnect layers, ${ }^{2}$ and phosphorus doped as an encapsulation layer. ${ }^{3}$ Both plasma and photon assisted CVD techniques have been used ${ }^{4-9}$ to deposit $\mathrm{SiO}_{2}$ at lower temperatures, at higher deposition rates and with improved step coverage compared to thermal CVD methods. The above nonthermal CVD techniques produce high quality films at substrate temperatures of $200-500^{\circ} \mathrm{C}$. This allows for reduction of thermal redistribution of dopant profiles, wafer warpage, and defect generation induced by high-temperature processes. These effects become increasingly important as semiconductor device structures are reduced to submicrometer dimensions. Prior to describing electron beam assisted CVD the properties of plasma and photon assisted CVD are briefly reviewed for purposes of comparison.

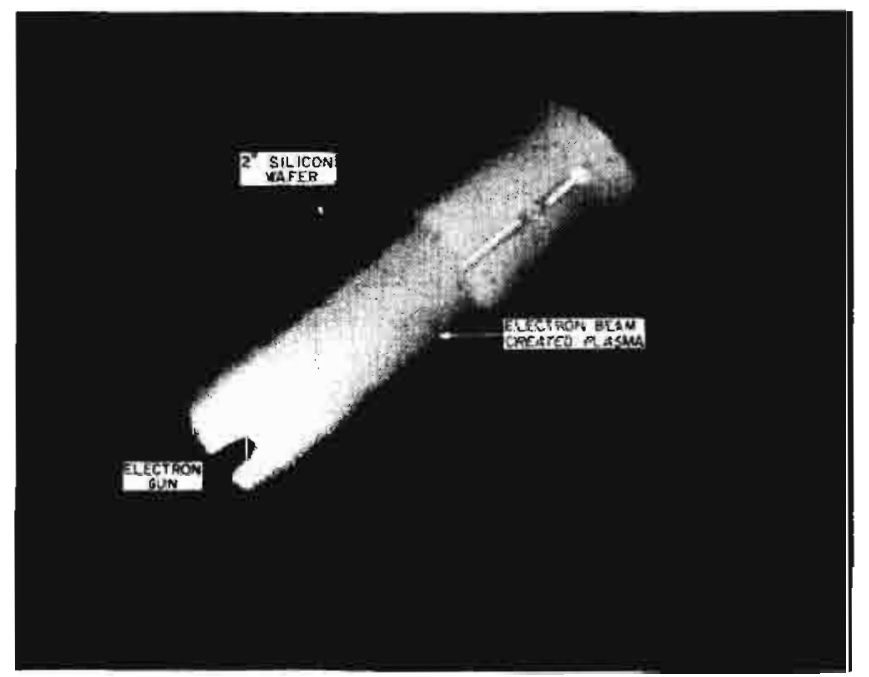

FIG. 1. Top view of plasma excitation caused by the 25 -mm-wide sheet electron beam traveling parallel to a $50-\mathrm{mm}$ silicon wafer.
In radio frequency plasma enhanced CVD the plasma fills the entire interelectrode volume; dissociated reactants are lost by deposition to the chamber walls, and undesired plasma sputtering from walls and fixtures occurs. ${ }^{4}$ Laserassisted CVD offers rapid deposition rates, a spatially localized deposition region and independence of both laser beam power and wavelength from reactor parameters such as gas flow rates and total gas pressures. ${ }^{6}$ With proper optics, a planar sheet of photons can be placed 1-2 mm above a substrate surface to initiate chemical reactions between donor gas molecules and minimize undesirable gas phase reactions. Laser-assisted CVD incorporates an expensive and energy inefficient source of photons needed for reactant dissociation. The electron beam assisted CVD (EBCVD) method introduced herein has a spatially localized excitation volume similar to laser assisted CVD, yet offers the potential for wide area depositions at high rates, and at lower cost.

Figure 1 is a top view of the electron beam produced plasma used to deposit silicon dioxide films. Due to the low scattering angle of kilovolt electrons, ${ }^{10}$ the reaction volume is sharply confined to a $25-\mathrm{mm}$-wide sheet as shown in Fig. 1. The electron beam source is a modified version of glow discharge electron guns originally developed to pump ion lasers. ${ }^{11}$ The cathode sheath accelerates the electrons to kilovolt energies with electron beam generation efficiencies up to $80 \%$.

Figure 2 illustrates the reactor geometry of the electron

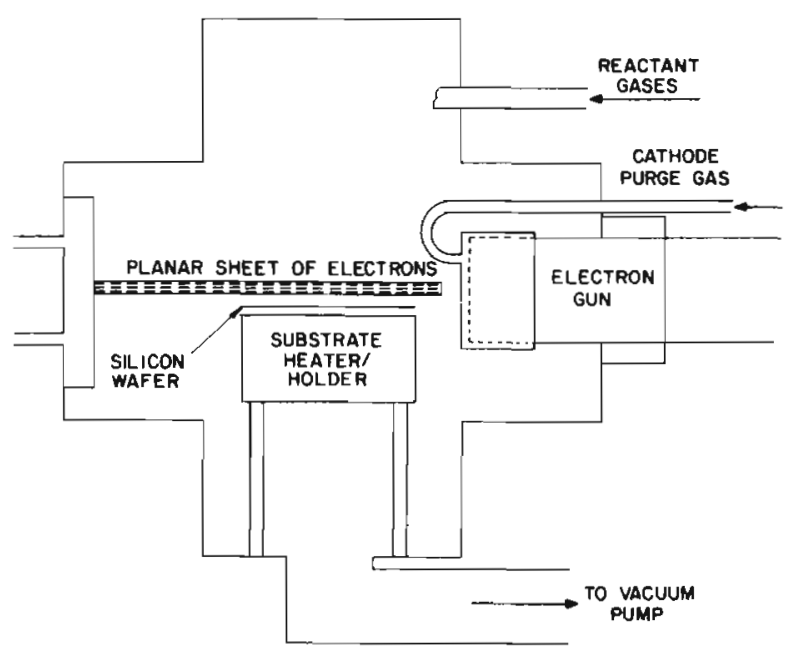

FIG. 2. Experimental arrangement of the electron beam deposition reactor. 


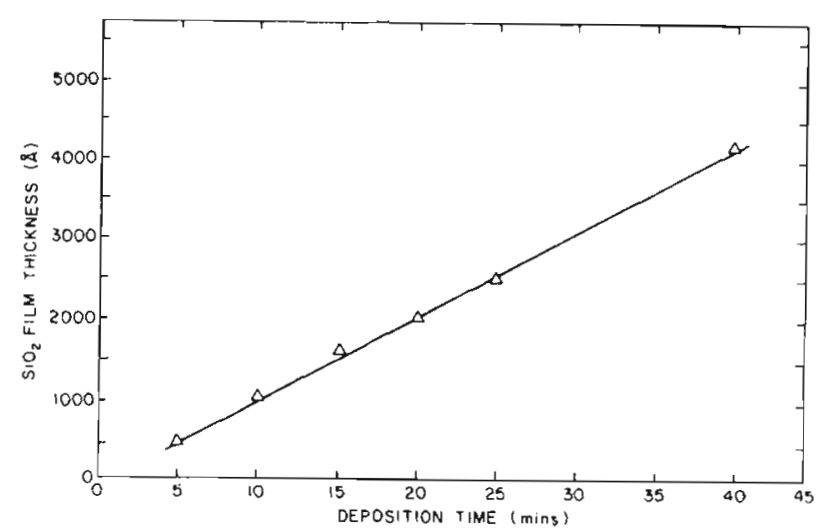

FIG. 3. $\mathrm{SiO}_{2}$ thickness vs electron beam deposition time.

beam deposition system. The electron beam travels parallel to and a few millimeters above a heated silicon wafer. A molybdenum plate heated by a 500-W tungsten halogen lamp in combination with a thermocouple controller provides variable substrate temperatures from 22 to $500^{\circ} \mathrm{C}$. Oxygen is used as a purge gas for the cathode face to maintain efficient electron emission from the glow discharge electron gun.

Typical silicon dioxide $\left(\mathrm{SiO}_{2}\right)$ deposition conditions for the electron beam CVD system are the following: substrate temperatures between 150 and $450^{\circ} \mathrm{C}$, total cell pressure between 0.1 and 1 Torr, $\mathrm{N}_{2} \mathrm{O}$ to $\mathrm{SiH}_{4}$ mass flow ratios between 25 and 100, and electron beam voltages between 1 and $5 \mathrm{kV}$ at current densities of $40-400 \mathrm{~mA} / \mathrm{cm}^{2}$. Deposited $\mathrm{SiO}_{2}$ films form stripes across the substrate corresponding to the 25-mm width of the electron beam created plasma. $\mathrm{SiO}_{2}$ films deposited with substrate temperatures of less than $150^{\circ} \mathrm{C}$ were powdery whereas films deposited with substrate temperatures above approximately $150^{\circ} \mathrm{C}$ were glasslike in agreement with results reported for the low-temperature laser photo CVD of $\mathrm{SiO}_{2}{ }^{6}$

Effects of reactant gas flow, electron beam current density, and deposition time on $\mathrm{SiO}_{2}$ film thickness have been investigated. Figure 3 shows $E B C V D \mathrm{SiO}_{2}$ film thickness as a function of time for a $\mathrm{N}_{2} \mathrm{O} / \mathrm{SiH}_{4}$ gas flow ratio of 75 , substrate temperature of $300^{\circ} \mathrm{C}$, and an electron beam current density of $160 \mathrm{~mA} / \mathrm{cm}^{2}$. A total gas pressure of $210 \mathrm{mTorr}$ was maintained at all flow rates by throttling the vacuum line. The oxide thickness varies linearly with deposition time. Less than $25 \AA$ of film growth occurred on the heated substrate under the same conditions after exposure times of 30 min with the electron beam off.

Figure 4 shows deposition rate as a function of electron beam current density for three $\mathrm{N}_{2} \mathrm{O}$ mass flows with a fixed $\mathrm{N}_{2} \mathrm{O} / \mathrm{SiH}_{4}$ mass flow ratio of 75, a substrate temperature of $300^{\circ} \mathrm{C}$, and a total chamber pressure of $250 \mathrm{~m}$ Torr. The increase in deposition rate with increased $\mathrm{N}_{2} \mathrm{O}$ flow with a fixed $\mathrm{N}_{2} \mathrm{O} / \mathrm{SiH}_{4}$ flow and chamber pressure indicates that the dissociation process is flow limited. The deposition rate appears constant over an order of magnitude change in electron beam current density but falls off at higher values. In an electron beam glow discharge, higher discharge voltages are necessary to achieve higher electron beam current densities. ${ }^{4}$ A $250 \mathrm{~m}$ Torr total pressure the electron energy increases

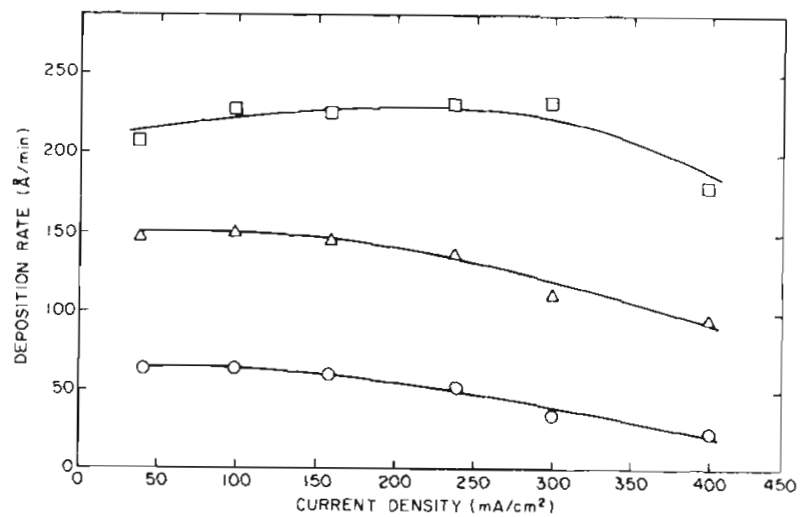

FIG. 4. $\mathrm{SiO}_{2}$ deposition rate vs electron beam current for three different gas flows with constant $\mathrm{N}_{2} \mathrm{O} / \mathrm{SiH}_{4}$ ratio of $75:$ (口) $\mathrm{N}_{2} \mathrm{O}=200 \mathrm{sccm}$; $/ \triangle$ i $\mathrm{N}_{2} \mathrm{O}=150 \mathrm{sccm} ;(\mathrm{O}) \mathrm{N}_{2} \mathrm{O}=100 \mathrm{sccm}$.

from 1 to $3 \mathrm{kV}$ as beam current density varies from 50 to 400 $\mathrm{mA} / \mathrm{cm}^{2}$. The small decrease in $\mathrm{SiO}_{2}$ deposition rate with increasing current is judged to occur because $\mathrm{SiH}_{4}$ and $\mathrm{N}_{2} \mathrm{O}$ reactants become more transparent to beam electrons due to the decrease in the electron collision cross sections at higher energies. $^{12}$

The physical and electrical properties were measured for the $\mathrm{SiO}_{2}$ films deposited with electron beam CVD on $n$ type single crystal silicon wafers with $\langle 100\rangle$ orientation and substrate resistivity of $5-10 \Omega-\mathrm{cm}$. $\mathrm{SiO}_{2}$ films deposited on 100 -mm silicon wafers at substrate temperatures from 150 to $450{ }^{\circ} \mathrm{C}$ had adherence values in excess of $10^{9}$ dynes $/ \mathrm{cm}^{2}$. Refractive indices of $\mathrm{SiO}_{2}$ films deposited with $\mathrm{N}_{2} \mathrm{O} / \mathrm{SiH}_{4}$ ratios from 30 to 100 were within $\pm 5 \%$ of the stoichiometric value of 1.462 . Wet chemical etch rates for EBCVD films of $36-60 \AA / \mathrm{s}$ are comparable with etch rates reported for laser deposited $\mathrm{SiO}_{2}$ films. ${ }^{6}$ Films produced by laser and electron deposition techniques have three to six times faster etch rates than thermally grown $\mathrm{SiO}_{2}$ films $(10-15 \AA / s)$ in 5:1 buffered HF. No annealing has been performed on the EBCVD films to date, but densification is expected to reduce etch rates as shown previously for other low-temperature CVD films. ${ }^{5,11}$

The electrical characteristics of metal-insulator-semiconductor (MIS) test structures for different EBCVD substrate temperatures are shown in Table $I$. The data in Table I were obtained from three runs at 250,350 , and $450^{\circ} \mathrm{C}$ substrate temperature with measurements at several locations on the wafer. The deposition conditions for these runs are 3.4 $\mathrm{kV}, 150 \mathrm{~mA}$ electron beam voltage, and current at 1.75 $\mathrm{mTorr} \mathrm{SiH}_{4}, 160 \mathrm{~m}$ Torr $\mathrm{N}_{2} \mathrm{O}, 25 \mathrm{mTorr}_{2} \mathrm{O}_{2}$, and $63 \mathrm{~m}$ Torr of $\mathrm{N}_{2}$ to give a total chamber pressure of $250 \mathrm{mTorr}$. The total deposition time was $25 \mathrm{~min}$, with a $\mathrm{N}_{2} \mathrm{O} / \mathrm{SiH}_{4}$ mass flow ratio of 75 . The substrate was $\langle 100\rangle n$-type single crystal silicon, with a sputtered Al back contact annealed at $425^{\circ} \mathrm{C}$ in forming gas prior to $\mathrm{SiO}_{2} \mathrm{EBCVD}$. The resistively evaporated $\mathrm{Al}$ front contacts to the $\mathrm{SiO}_{2}$ defined the area of the MIS capacitor $\left(\sim 0.02 \mathrm{~cm}^{2}\right)$. The thickness of the oxide, $T_{\mathrm{ox}}$ and the index of refraction $n_{\text {ox }}$ were measured with an ellipsometer. The substrate doping was calculated from $C_{\min }$ (1 $\mathrm{MHz}$ ) and $C_{\mathrm{ux}} \cdot{ }^{13}$ The fixed interface charge density $N_{r}$. was calculated from the equation 
TABLE I. Electrical properties of EBCVD films.

\begin{tabular}{|c|c|c|c|c|c|c|c|c|c|c|}
\hline $\begin{array}{c}\text { Substrate } \\
\text { temp } \\
\left({ }^{\circ} \mathrm{C}\right)\end{array}$ & $\begin{array}{c}\text { MIS } \\
\text { sample } \\
\text { location }\end{array}$ & $\begin{array}{l}N_{\text {sub }} \\
\left(\mathrm{cm}^{-3}\right) \\
\times 10^{14}\end{array}$ & $\begin{array}{l}T_{\mathrm{ox}} \\
(\AA)\end{array}$ & $\begin{array}{c}C_{\mathrm{FB}} \\
\left(\mathrm{F} / \mathrm{cm}^{2}\right) \\
\times 10^{-8}\end{array}$ & $\begin{array}{l}V_{\mathbf{F B}} \\
\text { (V) }\end{array}$ & $\begin{array}{c}N_{\text {fixed }} \\
\left(\# / \mathrm{cm}^{2}\right) \\
\times 10^{10}\end{array}$ & $\begin{array}{l}\text { Pinhole } \\
\text { density } \\
\left(\# / \mathrm{cm}^{2}\right)\end{array}$ & $\begin{array}{c}V_{B} \\
(\mathrm{MV} / \mathrm{cm})\end{array}$ & $\epsilon_{\mathrm{ox}}$ & $n_{o x}$ \\
\hline 250 & 1 & 10.9 & 1415 & 1.77 & 1.11 & 28 & 600 & 1.4 & 3.58 & 1.467 \\
\hline 250 & 2 & 10.0 & 1458 & 1.71 & 1.39 & 31 & & & 3.58 & 1.465 \\
\hline 250 & 3 & 8.8 & 1430 & 1.62 & 1.09 & 25 & & & 3.31 & 1.467 \\
\hline 250 & 4 & & 1420 & & & & & 3.3 & & \\
\hline 350 & 1 & 6.8 & 1949 & 1.32 & -0.13 & 8 & 760 & 2.1 & 3.61 & 1.469 \\
\hline 350 & 2 & 6.9 & 1974 & 1.23 & -0.36 & 5 & & & 3.35 & 1.467 \\
\hline 350 & 3 & & 1978 & & & & & 3.8 & & \\
\hline 450 & 1 & 8.4 & 1599 & 1.53 & 2.55 & 41 & 760 & 4.4 & 3.47 & 1.468 \\
\hline 450 & 2 & 6.6 & 1646 & 1.48 & 2.41 & 39 & & & 3.54 & 1.466 \\
\hline 450 & 3 & 7.3 & 1665 & 1.49 & 2.59 & 41 & & & 3.57 & 1.467 \\
\hline 450 & 4 & & 1665 & & & & & 2.8 & & \\
\hline
\end{tabular}

$$
N_{F}=\left(C_{\mathrm{ox}} / q\right)\left(\phi_{\mathrm{MS}}-V_{\mathrm{FB}}\right),
$$

where $C_{\mathrm{O} x}$ is the oxide capacitance density, $V_{\mathrm{FB}}$ is the voltage at the flatband capacitance $\left(C_{\mathrm{FB}}\right)$, and $\phi_{\mathrm{MS}}$ is the metal-semiconductor work function difference. ${ }^{14}$ The values measured for the dielectric constant, $\epsilon_{\mathrm{ox}}(\sim 3.5)$ shown in Table I are lower than values obtained from thermal $\mathrm{SiO}_{2}$ films $(\sim 3.8)$.

Current versus voltage $(I-V)$ measurements were performed on the EBCVD $\mathrm{SiO}_{2}$ MIS capacitors in accumulation. The pinhole density was measured with an electrophoretic tester. Catastrophic breakdown occurred at $>5 \mathrm{MV} /$ $\mathrm{cm}$, with self-healing breakdown events occurring in the 2$5-\mathrm{MV} / \mathrm{cm}$ range, presumably due to pinholes. The values listed in Table $I$ for $V_{B}$ were taken at the first breakdown event. Infrared transmission spectra of $0.6-\mu$-thick EBCVD films deposited at $300{ }^{\circ} \mathrm{C}$ show characteristic $\mathrm{SiO}_{2}$ peaks with no measurable absorbance due to $\mathrm{SiOH}, \mathrm{H}_{2} \mathrm{O}$, or $\mathrm{SiH}$ groups at 3650,3300 , or $2270 \mathrm{~cm}^{-1}$ respectively ${ }^{15}$ which is consistent with the low etch rates of the deposited films.

Summarizing an electron beam assisted CVD technique using a unique sheet beam geometry is demonstrated for the first time. Preliminary $\mathrm{SiO}_{2}$ deposition conditions and deposited films have been characterized. Other thin films such as amorphous or polycrystalline silicon, silicides, as well as metallic films may also be deposited with the electron beam induced chemical vapor deposition (CVD) technique introduced here. Electron beam assisted CVD offers the possibility of uniform deposition over large areas using a confined plasma region that is located several millimeters above the substrate surface.
This work was supported by the National Science Foundation, the Office of Naval Research, ASM, and NASA-Lewis. K. Emery and P. Boyer are ASM America Industrial Research Fellows. We thank Dave Mills of H.P., Loveland, $\mathrm{CO}$ for providing silicon wafers and Laura Pagano for C-V measurements. Bill Ritchie of NCR Microelectronics (Fort Collins) provided pinhole density measurements.

'J. Y. Chen, R. C. Henderson, J. T. Hall, and E. W. Yee, Tech. Dig. IEEE Int. Electron Devices Meetings 233 (1982).

${ }^{2}$ Brad Mattson, Solid State Technol. 23, 60 (1980).

${ }^{3}$ G. Schnable, W. Keru, and R. B. Comizzoli, J. Electrochem. Soc. 122, 1092 (1975).

${ }^{4}$ Richard S. Rosler and George M. Engle, Solid State Technol. 22, 88 (1979); W. Kern and R. S. Rosler, J. Vac. Sci. Technol. 14, 1082 (1977).

${ }^{5}$ R. M. Levin and K. Evans-Lutterodt, J. Vac. Sci. Technol. B 1, 54 (1983).

${ }^{6}$ P. K. Boyer, G. A. Roche, W. H. Ritchie, and G. J. Collins, Appl. Phys. Lett. 40, 716(1982); P. K. Boyer, W. H. Ritchie, and G. J. Collins, J. Electrochem. Soc. 129, 2155 (1982).

'J. W. Peters, Tech. Dig. IEEE Int. Electron Devices Meeting 240 (1981).

${ }^{8}$ R. P. H. Chang and S. Darack, Appl. Phys. Lett. 42, 272 (1983).

${ }^{9}$ L. G. Meineis, J. Vac. Sci. Technol. 21, 655 (1982).

${ }^{10} \mathrm{H}$. Massey and E. Burhop, Electronic and Ionic Impact Phenomena (Oxford University, London, 1969), Vol. 1.

' 'Zeng qu Yu, J. Rocca, D. Meyer, and G. J. Collins, J. Appl. Phys. 53, 4704 (1982); J. J. Rocca, J. D. Meyer, A. Yu, M. Farrell, and G. J. Collins, Appl. Phys. Lett. 41, 811 (1982).

${ }^{12}$ J. Perrin, J.Schmitt, G. de Rosny, B. Drevillon, and J. Huc, Chem. Phys. (to be published).

${ }^{13}$ B. E. Deal, A. S. Grove, E. H. Snow, and C. T. Sah, J. Electrochem. Soc. 112, 308 (1965).

${ }^{14}$ S. M. Sze, Physics of Semiconductor Devices (Wiley, New York, 1979).

${ }^{15}$ W. A. Pliskin, J. Vac. Sci. Technol. 14, 1064 (1977). 